\title{
ALEITAMENTO MATERNO NA PERSPECTIVA DE MÃES ADOLESCENTES: CONTRIBUIÇÕES PARA ATENÇÃO PRIMÁRIA À SAÚDE
}

\section{MATERNAL BREASTFEEDING FROM THE ADOLESCENT MOTHERS' PERSPECTIVE: CONTRIBUTIONS FOR PRIMARY HEALTH CARE}

\section{LACTANCIA MATERNA EN LA PERSPECTIVA DE MADRES ADOLESCENTES: CONTRIBUCIONES PARA ATENCIÓN PRIMARIA A LA SALUD}

Angela Mendes Taveira ${ }^{1}$, Alisson Araújo ${ }^{2}$.

\begin{abstract}
RESUMO
Objetivo: Compreender, a partir dos relatos das mães adolescentes, os sentimentos, o apoio recebido e suas dificuldades na prática do Aleitamento Materno. Método: Estudo qualitativo de abordagem interpretativa, desenvolvido através de entrevistas semiestruturadas. As participantes do estudo foram 12 mães adolescentes com filhos em idade de 2 a 12 meses. Resultados: As entrevistadas discorrem que, em meio a reações (de responsabilização, preconceito, autoestima melhorada, restrição social e vínculo mãe-bebê), receberam algum apoio na amamentação e reconhecem sua importância. Porém, relataram ainda muitas dificuldades. Isso demonstra que, na verdade, o apoio ofertado ainda é muito incipiente. Os discursos decorrem, não apenas, das dificuldades inerentes das mães adolescentes, mas também do reflexo da falta de apoio e acompanhamento adequados, principalmente dos profissionais de saúde, no processo de amamentação, destacando sua condição de mãe adolescente. Conclusão: Percebe-se a necessidade de orientação e apoio adequados dos profissionais de saúde e da família da adolescente. Portanto, é necessário um acompanhamento que deve ser iniciado no pré-natal e desenvolvido ao longo do tempo de forma contínua, dinâmica, processual e interativa, favorecendo também a autonomia e corresponsabilização dos envolvidos, principalmente dos profissionais da atenção primária à saúde no que diz respeito à adolescência e ao aleitamento materno. Descritores: Adolescente; Gravidez na adolescência; Aleitamento materno; Família; Pessoal de saúde.
\end{abstract}

\section{ABSTRACT}

Objective: To understand, from the adolescent mothers' reports, the feelings, the received support and their difficulties in the practice of breastfeeding. Methods: Qualitative study of interpretative approach developed through semi structured interviews. The study participants were 12 adolescent mothers with children whose ages are between 2 and 12 months. Results: The interviewees say that among their reactions (accountability, prejudice, improved self-esteem, social restriction and mother-baby bond), they received some support on breastfeeding and recognized its importance. However, they reported many difficulties. This shows that, in fact, the offered support is still very rudimentary. The discourses stem not only from the inherent difficulties of adolescent mothers, but also from the lack of adequate support and follow-up, especially from health professionals, in the breastfeeding process, highlighting their status as adolescent mother. Conclusion: The need for adequate guidance and support of health professionals and the adolescent family is evident. Therefore, it is necessary a follow-up which should be started in the prenatal care and developed over time in a continuous, dynamics, procedural and interactive way, also favoring autonomy and coresponsibility of those involved, especially the Primary Health Care professionals concerning adolescence and breastfeeding. Keywords: Adolescent; Teenage pregnancy; Breastfeeding; Family; Health personnel.

\section{RESUMEN}

Objetivo: Comprender, a partir de los relatos de las madres adolescentes, los sentimientos, el apoyo recibido y sus dificultades en la práctica de la Lactancia Materna. Método: Estudio cualitativo de enfoque interpretativo, desarrollado a través de entrevistas semiestructuradas. Los participantes del estudio fueron 12 madres adolescentes con hijos en edad de 2 a 12 meses. Resultados: Las entrevistadas discuten que en medio de reacciones (de responsabilidad, preconcepto, autoestima mejorada, restricción social y vínculo madre-bebé) recibieron algún apoyo en la lactancia y reconocen su importancia. Sin embargo, relataron muchas dificultades. Esto demuestra que, en realidad, el apoyo ofrecido todavía es muy incipiente. Los discursos se derivan no sólo de las dificultades inherentes de las madres adolescentes, sino también del reflejo de la falta de apoyo y acompañamiento adecuados, principalmente de los profesionales de salud, en el proceso de lactancia, destacando su condición de madre adolescente. Conclusión: Se percibe la necesidad de orientación y apoyo adecuados de los profesionales de salud y de la familia de la adolescente. Por lo tanto, es necesario un seguimiento que debe ser iniciado en el prenatal y desarrollado a lo largo del tiempo de forma continuada, dinámica, procesal e interactiva, favoreciendo también la autonomía y corresponsabilidad de los involucrados, principalmente de los profesionales de la atención primaria a la salud cuando se refiere a la adolescencia y a la lactancia materna. Descriptores: Adolescente; Embarazo en adolescencia; Lactancia materna; Familia; Personal de salud.

${ }^{1}$ Graduada e Mestre em Enfermagem pela Universidade Federal de São João del-Rei. ${ }^{2}$ Graduado em Enfermagem e Doutor em Saúde da Criança e do Adolescente pela Universidade Federal de Minas Gerais. Docente na Universidade Federal de São João del-Rei.

\section{Como citar este artigo:}

Taveira AM, Araújo A. Aleitamento materno na perspectiva de mães adolescentes: contribuições para Atenção Primária à Saúde. Revista de Enfermagem do Centro oeste Mineiro. 2019; 9: e3118. [Access http://dx.doi.org/10.19175/recom.v9i0.3118 


\section{INTRODUÇÃO}

A adolescência ${ }^{(1)}$, fase que abrange a faixa etária dos 10 aos 19 anos, é o período de transição entre a infância e a vida adulta, caracterizado por desenvolvimento físico, cognitivo, social, emocional e sexual, exigindo, assim, atenção especial nas políticas, programas e planos nacionais de desenvolvimento.

Em decorrência das transformações biológicas, psicológicas e sociais desta fase, os adolescentes podem apresentar vulnerabilidade a comportamentos de vida que podem deixá-los mais expostos a riscos, tais como o uso de álcool, fumo e outras drogas, Infecções Sexualmente Transmissíveis/Síndrome da Imunodeficiência Adquirida (IST/AIDS) e gravidez na adolescência fenômeno de grande importância e relevância social $^{(2)}$.

Dentre os riscos aos quais essa população está exposta, o fenômeno da gravidez na adolescência é compreendido como um processo que repercute de forma ampla sobre o desenvolvimento biopsicossocial do adolescente. É considerado como um fato precoce para essa etapa da vida que, geralmente, pode resultar em sérias implicações, como riscos para o feto e para a mãe, abandono das atividades escolares e projetos de vida, conflitos familiares, discriminação social e afastamento de grupos de convivência ${ }^{(3)}$.

Embora haja, mundialmente, uma redução na prevalência da gravidez nesse grupo etário ${ }^{(4)}$, em países subdesenvolvidos, todos os anos, cerca de 16 milhões de meninas com idades entre 15 e 19 anos e cerca de um milhão de meninas menores de 15 anos tornam-se mães, além de provocar um impacto negativo sobre a família e a sociedade $^{(5)}$.

No Brasil, as ocorrências de gravidez na adolescência têm gerado discussões e preocupação no âmbito da Saúde Pública, principalmente devido ao aumento significativo da fecundidade na faixa etária entre 10 e 14 anos. Estima-se que, um milhão de nascidos vivos a cada ano têm mães com idade entre 10 e 19 anos, o que corresponde a $19 \%$ do total de nascidos vivos no País ${ }^{(6)}$. Em Divinópolis/Minas Gerais (MG), apesar da redução de gravidez na adolescência (12,29\% em 2006 para 9,57\% em 2016), anualmente, no município, nascem em torno de 250 crianças filhas de mães adolescentes $^{(7)}$.

Esse quantitativo de mães adolescentes e seus bebês demandam, assim, inúmeros cuidados das equipes da Atenção Primária à Saúde (APS), incluindo o fundamental acompanhamento do processo de amamentação. A amamentação representa a oferta de leite materno diretamente na mama da nutriz e difere de aleitamento materno (AM), o qual envolve todas as formas do lactente receber o leite materno, seja na mama ou ordenhado ${ }^{(8)}$.

A Organização Mundial de Saúde (OMS) recomenda que o Aleitamento Materno Exclusivo (AME) seja oferecido até o sexto mês. A indicação da OMS, com base em estudos científicos, é de que o Leite Materno (LM) até essa idade é um alimento completo em todas as circunstâncias, seja a mãe de países pobres ou não e, a partir de seis meses de vida, o LM seja complementado com alimentação oportuna e adequada, até os dois anos de idade ou mais ${ }^{(9)}$.

Nem sempre as mães adolescentes estão preparadas para assumir a responsabilidade de serem mães, para cuidarem de seus bebês de forma adequada e suprir suas necessidades. $O$ aleitamento materno de mães adolescentes, de forma especial nos primeiros meses de vida, promove o valioso contato mãe-filho; sendo assim algo de extrema importância que pode contribuir para o adequado desenvolvimento da criança e o bom relacionamento maternoinfantil $^{(10)}$.

Para a mãe adolescente, a amamentação pode se configurar um grande desafio, pois além de lidar com as modificações e adaptações próprias da fase adolescência (crescimento físico rápido, mudanças hormonais, desenvolvimento sexual, emoções novas e complexas, aumento das capacidades cognitivas e intelectuais, desenvolvimento moral e evolução das relações com seus pares e famílias) ${ }^{(1)}$, ela terá que desenvolver seu papel materno que, naturalmente, inclui a prática do aleitamento materno.

Esse contexto pode ser desafiador para as mães adolescentes, pois embora seja um processo natural, amamentar não é apenas instintivo, envolve um aprendizado e, por isso, requer prática e tempo para ser aprimorado. Constitui importante forma de contato íntimo e de proteção entre a mãe e o recém-nascido, com diversas vantagens aos mesmos ${ }^{(8)}$.

Desse modo, é responsabilidade dos profissionais da saúde que atendem às adolescentes no pré-natal, incentivá-las e orientálas quanto à prática do aleitamento materno exclusivo até o sexto mês de vida do recém- 
nato $^{(11)}$. A orientação quanto à amamentação precisa ser desenvolvida por meio do compartilhamento de conhecimentos e da negociação do saber científico com o popular para, a partir daí, serem construídas possibilidades para as melhores decisões em saúde para a mãe e o bebê $\hat{~}^{(12)}$.

Destarte, o presente estudo busca compreender os sentimentos, o apoio recebido e as dificuldades na prática do Aleitamento Materno na perspectiva de mães adolescentes. Procurou-se uma compreensão a partir dos relatos para fundamentação de uma proposta assistencial às adolescentes que consolide estratégias de ação no cotidiano dos serviços de saúde.

\section{MÉTODO}

Com o intuito de compreender as dificuldades, os sentimentos e as expectativas vivenciadas pela mãe adolescente na prática do AM, optou-se por uma pesquisa de natureza descritiva e abordagem qualitativa ${ }^{(13)}$.

A pesquisa foi realizada no âmbito das 32 UBS de Divinópolis, município do Centro-Oeste mineiro, com população estimada, no ano de 2018, de 235.977 habitantes ${ }^{(14)}$. As participantes elegíveis do estudo foram todas as puérperas e nutrizes adolescentes (10 a 19 anos), que tivessem filho com a idade de 2 a 12 meses no período de junho a agosto de 2015, acompanhadas pelas UBS do município e identificadas através do Sistema de Informação da Assistência Pré-natal (SIS PRENATAL) e do Sistema de Informação sobre Nascidos Vivos (SINASC). Através desses dois sistemas de informação, foram obtidas listagens de mães de 10 a 19 anos por UBS. Essas mães adolescentes foram visitadas e convidadas a participar da pesquisa. As visitas foram realizadas de forma alternada entre as UBS de modo à participação de mães adolescentes das mais diversas regiões do município.

Como técnica de coleta de dados, foi utilizada a entrevista semiestruturada, que contou com a utilização de um roteiro previamente definido. O roteiro constava de 6 perguntas norteadoras, abertas, elaboradas pelos autores e versavam sobre o significado do AM para a adolescente, assim como o conhecimento, as dificuldades e facilidades da prática do AM. As entrevistas foram desenvolvidas junto às puérperas e nutrizes adolescentes, tendo essas e seu responsável legal, assinado previamente o
Termo de Consentimento Livre e Esclarecido (TCLE) e o Termo de Assentimento, para que os aspectos éticos da confiabilidade e privacidade, nesta pesquisa, estejam assegurados de acordo com a Resolução no 466/12 sobre pesquisa envolvendo seres humanos. A pesquisa foi aprovada no Comitê de Ética em Pesquisa sob CAAE 44377815.2.0000.5545.

Para preservar 0 anonimato das entrevistadas, as mesmas foram nominadas por pedras preciosas brasileiras. Ao final de cada entrevista, foi perguntado a cada mãe adolescente se gostaria de ouvir o áudio e se teria algo a perguntar.

As entrevistas, com tempo médio de 30 a 40 minutos, foram realizadas no domicílio das entrevistadas. $O$ critério para o término da coleta de dados foi quando os discursos se tornaram repetitivos, mostrando a saturação dos dados, delimitando assim os participantes em 12 puérperas/nutrizes adolescentes. Os discursos foram gravados em áudio, transcritos, e o material alcançado submetido à Análise de Conteúdo, que é feita por meio da leitura das descrições do princípio ao fim, para se ter o sentido do todo através de um procedimento de reflexão ${ }^{(15)}$.

Foram identificados os menores recortes dos discursos (unidades de registro), sendo escolhidos com base nos objetivos da pesquisa e que significam algo a respeito do objeto de estudo abordado. Obedecendo a pertinência temática e correlação, essas unidades de registro permitiram construir quatro categorias analíticas, a saber: 1. Perfil das mães adolescentes e o impacto social da gravidez na adolescência; 2 . Reações sobre a vivência da adolescência/maternidade/amamentação; 3. A importância do apoio familiar e profissional no processo do aleitamento materno; e 4. As dificuldades encontradas pelas mães adolescentes durante a amamentação.

\section{RESULTADOS E DISCUSSÃO}

Perfil das mães adolescentes e o impacto social da gravidez na adolescência

A idade média das 12 mães adolescentes participantes do estudo foi de 17 anos. Todas essas mães fizeram pré-natal, sendo a minoria (25\%) em consultório particular e a maioria (75\%) em serviço público municipal. Oito delas moravam com a família e seu filho, sem o companheiro e quatro moravam com o filho e o pai da criança. 
Engravidar nessa idade, em que ainda não foi alcançada a emancipação financeira, pode deslocar a dependência da adolescente da família de origem, para o pai da criança. Assim, por enfrentarem, geralmente, limitações financeiras, a realização de acompanhamento pré-natal em serviço público de saúde acaba sendo importante alternativa. De forma geral, a gravidez nessa fase não é intencional e acontece em meio a relacionamentos sem estabilidade. Nos últimos anos, ocorreram muitas mudanças quanto ao comportamento dos indivíduos, particularmente no que se refere ao aumento da atividade sexual entre os adolescentes, levando a um aumento de gravidez, muitas vezes, não planejada ${ }^{(16)}$.

Entre as participantes da pesquisa, quase todas relataram não ter planejado a gravidez: "Eu tenho dois filhos. O primeiro tem dois anos. Nenhuma das gravidezes foi planejada" (Ágata). "Sim, é minha primeira gravidez. A gente não tinha planejado, mas já que veio, foi bem vindo" (Turquesa). "É minha primeira gravidez. Não foi planejada, eu descobri com cinco pra seis meses" (Ônix). "Não foi planejada, mas já que veio, foi bem vindo, né?" (Água Marinha).

As reflexões sobre o planejamento da gravidez são valiosas e por estarem na adolescência, elas necessitam pensar se esse momento é o mais oportuno e ideal para engravidarem, até mesmo para enfrentarem novas situações. Neste estudo, a maioria (67\%) parou de estudar, atribuindo, como motivo, a gravidez, ou devido ao preconceito existente em relação à gravidez na adolescência: “(...) mas, depois que eu fiquei grávida, por ser nova, têm pessoas que se afastam. Mas aí a gente percebe quem são os amigos de verdade" (Ametista). "Na escola, as minhas notas diminuíram bastante quando eu soube que tava grávida" (Jade). "Na escola, eles fica falando que a gente é piriguete, que a gente arrumou menino cedo (...)" (Opala).

Em função do estresse causado pela gravidez e redução da autoestima, em decorrência da reprovação por parte da sociedade, dentre outros fatores, muitas adolescentes grávidas acabam por perderem o estímulo pelos estudos, podendo levá-las a reduzirem o rendimento escolar ou, em situação mais crítica, a abandonarem os estudos ${ }^{(17)}$.

\section{Reações sobre a vivência da adolescência/ maternidade/amamentação}

Uma gestação implica diversas alterações tanto físicas como emocionais para a mulher.
Quando ela acontece na adolescência, as modificações normais de uma gravidez serão somadas aos conflitos próprios dessa faixa etária. Porém, esta é uma temática que merece estudos em diferentes perspectivas, pois cada adolescente atribui, ao processo maternal, significados que variam de acordo com sua inserção familiar e social ${ }^{(18)}$.

As mães participantes desta pesquisa expressaram reações diversas em relação à maternidade na adolescência e amamentação, tais como responsabilização, preconceito, autoestima melhorada, restrição social, vínculo mãe-bebê, dentre outros: "Eu sempre saí com meus amigos. Mas, agora que tem filho, é mais difícil, quase eu não saio (...) ele gostava de mamar (risos) até tranquilizava ele na hora que ele tava chorando" (Ágata). "Amamentar, para mim, é uma forma que eu estou protegendo ela, sabe? É sentir que ela precisa mesmo de mim (...) Por eu ter ficado grávida jovem, aí alguns se afastaram, até ficavam falando" (Ametista).

"Quando eu soube que tava grávida, nossa senhora, eu fiquei, eu mudei totalmente, sabe? 0 meu comportamento assim, eu não ligava pra nada, não me arrumava, não conversava com as pessoas direito. E depois eu fui mudando, percebendo que realmente eu tava grávida" (Jade). "Porque eu parei de estudar, né? Parei de estudar, parei tudo. Aí eu só fiquei o tempo pra ela. Só ficava dentro de casa" (Topázio). "Eu queria casar com meu namorado, aí meus pais adotivos não deixaram. Então eu engravidei pra casar, porque a gente queria casar" (Turmalina).

A experiência da amamentação possibilita, conforme apontado pelas participantes, o fortalecimento do vínculo afetivo entre mãebebê. A mãe adolescente vivencia, além das mudanças próprias da idade como as físicas, sociais e psicológicas, também, as gravídicaspuerperais. A amamentação prazerosa, o olho no olho e o contato contínuo entre mãe e filho fortalecem os laços afetivos entre eles, oportunizando intimidade, troca de afeto e sentimentos de segurança e de proteção ${ }^{(8)}$.

Mesmo havendo uma ambiguidade de sentimentos que perpassam esse período, estudo realizado com adolescentes primíparas demonstrou que, embora possam existir dificuldades no início da amamentação, muitas mães a percebem como uma experiência repleta de significados positivos. A mãe adolescente se sente empoderada com a amamentação e 
considera que ela auxilia na construção da maternagem ${ }^{(19)}$.

Uma compreensão melhor sobre o que significa a gravidez e a maternidade para a mãe adolescente nos permite um planejamento mais eficiente da assistência à saúde desta adolescente, incluindo aqui o sucesso do aleitamento materno.

Como observado, preconceito e restrição social fazem parte do cotidiano das mães adolescentes estudadas. Os estigmas gerados desses contextos podem repercutir sobre a autoestima e empoderamento da mãe adolescente, diminuindo sua capacidade de julgar-se capaz de amamentar seu filho. Experiências como estresse e ansiedade podem reduzir a confiança da mãe em amamentar ${ }^{(20)}$.

\section{A importância do apoio familiar e profissional no processo do aleitamento materno}

A maioria das mães entrevistadas referiu o apoio, principalmente da mãe, como um fator essencial para terem amamentado, independente da duração dessa prática. $\mathrm{E}$, demostraram que se não tivessem esse apoio, provavelmente não teriam continuado a amamentar: "Minha mãe me apoia amamentar, ela pede que eu amamente até... até eu conseguir mesmo, enquanto eu tiver leite ainda. Minha mãe amamentou nós três" (Ametista). "Eu queria parar de amamentar, até que minha mãe falou "não, tem que amamentar pelo menos até os 9 meses" (Pérola). "Uai, tendo o apoio da minha mãe e do meu pai, facilita muito" (Granada). "Ele (o namorado) também achava muito importante, ele falava pra não deixar de espécie nenhuma de amamentar o bebê" (Esmeralda). "Eu ia lá no posto porque não tava dando conta de dar mamar pra ele, aí elas (enfermagem) me ensinaram" (Turquesa).

A amamentação é uma prática impregnada por ideologias socioculturais, apresenta-se como processo complexo, no qual inúmeros determinantes a influenciam e cuja complexidade é vivenciada de forma diferente por cada adolescente $^{(21)}$. No cotidiano familiar, as avós, geralmente, auxiliam nos cuidados a serem dispensados ao binômio mãe-filho, podendo contribuir na resolução de problemas que surgem no processo de amamentação. Para isso, utilizam seus saberes adquiridos em experiências anteriores na prática da amamentação ${ }^{(21)}$.

As 12 mães fizeram pré-natal, sendo que a maioria fez em Unidades Básicas de Saúde. Apenas cinco relataram ter tido informação sobre o preparo da mama e a prática da amamentação no pré-natal. Mesmo com dificuldades, somente três delas buscaram ajuda de profissionais de saúde. As demais foram auxiliadas por familiares.

A amamentação na adolescência conclama apoio da família e dos profissionais de saúde para auxiliarem a mãe adolescente no enfrentamento dos obstáculos aos novos reajustes demandados com a maternidade e o $\mathrm{AM}^{(22)}$. Diante dessa realidade, os profissionais de saúde precisam apoiar e incentivar a mãe adolescente, identificando precocemente suas dificuldades na amamentação e estabelecendo condutas necessárias para cada caso. Este trabalho de incentivo deve ser contínuo e é importante que os profissionais de enfermagem sejam conscientes dessa ação e que suas atuações tenham como meta que as mães adolescentes se sintam suficientemente informadas e apoiadas para tomarem as melhores decisões acerca da amamentação de seus filhos ${ }^{(23)}$.

Nesta pesquisa, apenas cinco delas obtiveram alguma informação sobre AM durante o pré-natal. O que reforça a importância do papel educativo no pré-natal, o acompanhamento e apoio dessas mães no pós-parto pelos familiares e profissionais de saúde para que elas consigam se expressar e superar as dificuldades. Ressalta-se que a amamentação é uma habilidade, uma arte a ser aprendida e reaprendida. Para tanto, a adolescente necessita ser estimulada a aprender, assim como apoiada e ensinada ${ }^{(24)}$.

\section{As dificuldades encontradas pelas mães adolescentes durante a amamentação}

Todas as participantes relataram algum tipo de dificuldade para amamentar. Dentre essas dificuldades que influenciaram no processo de amamentação, as adolescentes mencionaram o trauma mamilar, fator de muita ocorrência entre as entrevistadas. "O peito também feriu muito no início... Eu amamento, não dou mais nada, só o leite do peito" (Jade). "Ah, o meu peito rachou muito. Mesmo assim, eu amamentei. Porque meu peito rachou muito, eu dava mama, ele até sangrava. Aí depois que parou, ficou normal" (Opala). "O peito feriu bem no início, no começo" (Esmeralda). "No começo rachou muito e eu sentia muita dor, mas dei mamá assim mesmo" (Turmalina).

O trauma mamilar é causa comum para a maioria dos casos de abandono do aleitamento materno por ocasionar dor e desconforto às puérperas. Dentre os fatores que propiciam o 
problema, estão a preensão e posicionamento do recém-nascido para a mamada, a primiparidade, a ausência do companheiro, as mamas em condições túrgidas e ingurgitadas e outros ${ }^{(25)}$. Visando o conhecimento em amamentação que pode prevenir essa intercorrência, as adolescentes deverão ser capacitadas pelos profissionais de saúde sobre a técnica da amamentação e suas vantagens para a saúde da mãe e do filho(2).

Tanto em atendimentos individuais quanto em visitas domiciliares ${ }^{(8)}$, preferencialmente nas primeiras 24 horas após retorno ao domicílio, deve ser realizado apoio à continuação da amamentação com resolução das dificuldades que surgirem $^{(2)}$.

As adolescentes também referiram que eram comuns problemas relacionados à pega mamária. "No começo, ele não queria pegar o peito, aí eu fui ficando sem paciência com ele" (Esmeralda). "(...) aí dificultou muito porque ele quase não pegava, ficava chorando muito" (Jade). "Ela não pega direito o bico do peito" (Ônix). "No começo, foi assim, que doía muito, né? Saía até sangue, porque ela não sabia pegar direito o peito" (Granada).

A dor decorrente da fissura mamária constituiu uma das principais dificuldades do ato de amamentar. As mães adolescentes expressaram ter tido dificuldades na amamentação, principalmente no seu início, quando ainda não havia sido estabelecida a pega mamária. A dificuldade da pega, devido a posição inadequada, pode gerar dor e traumas mamilares, assim como choro e irritabilidade na criança, o que pode desmotivar para a amamentação e ocasionar o desmame precoce ${ }^{(8)}$.

Outra dificuldade relatada pelas adolescentes diz respeito ao tamanho do seio. "É porque por eu ser muito nova, ela não tem pega direito. É porque é pequeno - seio" (Ônix). "Dificultou porque eu quase não tinha seios, aí dificultou muito" (Jade).

O tamanho da mama não tem relação com a produção do leite ${ }^{(8)}$ e, para que haja sucção efetiva, a criança deve estar com o rosto de frente para o peito, com o seu abdômen encostado no da mãe, sugando o seio abocanhando mamilo e parte da aréola ${ }^{(2)}$. Caso a pega seja só no mamilo, pode haver erosão e/ou fissura mamilar por fricção continuada, além de que, sem a pressão dos ductos lactíferos contra o palato, não há saída adequada de leite, levando a mulher a acreditar que tem pouco leite, sentir dor, podendo então ser desencadeado o processo de desmame precoce ${ }^{(26)}$. "Ficava chorando muito, também não tinha leite, depois que o leite foi juntando" (Jade). "Machucou muito, aí eu tive que parar de tirar e dava outro leite" (Topázio). "Não, não foi fácil. (...) e nos primeiros dias, ele não pegava o peito. Aí o meu leite era fraco eu tive que tá dando outras coisas" (Água Marinha).

As mães adolescentes, por vezes, apresentam dificuldades com a amamentação, as quais são prevalentes nos primeiros dez dias de vida do bebê em comparação às fases subsequentes do puerpério ${ }^{(22)}$.

Um estudo brasileiro ${ }^{(20)}$ realizado com mães adolescentes em São Paulo/SP detectou prevalência de AME de 62\% em 30 dias, 52,59\% em 60 dias e 16\% em 180 dias pós-parto. Isso denota a necessidade de esforços, por parte dos profissionais de saúde, para que as adolescentes que passam por intercorrências nesses períodos sejam acolhidas e auxiliadas para a realização da amamentação de forma prazerosa e efetiva, tanto para elas quanto para seus filhos.

Os profissionais de saúde envolvidos durante o ciclo gravídico-puerperal da mulher precisam discutir e desmistificar práticas que possam levar ao desmame precoce, assim como auxiliar às mães adolescentes a lidar com as dificuldades que podem advir da amamentação. É preciso que a mulher acredite na sua capacidade tanto de produzir leite ao seu bebê quanto de manter com êxito a amamentação, o que pode influenciar diretamente na concretização do ato de amamentar ${ }^{(12)}$.

Entre as mães participantes do estudo, cinco estavam amamentando até o momento da entrevista. A média de AME dessas mães foi de noventa e oito dias, ou seja, a metade da meta estipulada ${ }^{(8)}$ pela OMS, que é 180 dias. Somente três participantes desta pesquisa praticaram o AME até o sexto mês de vida.

\section{CONCLUSÃO}

A análise dos discursos das entrevistadas permitiu, a partir dos seus relatos sobre os fatores que influenciam o processo da amamentação, melhor compreensão sobre as dificuldades, os sentimentos e as expectativas das adolescentes que amamentam. A identificação desses fatores é importante para que a mãe adolescente seja auxiliada no enfrentamento dos obstáculos que possam surgir, bem como, na construção de sua autonomia para a decisão de amamentar. 
Diante dos relatos, percebeu-se que as causas de desmame precoce, nessas mães adolescentes, estão relacionadas com as dificuldades para amamentar durante os primeiros dias devido aos traumas mamilares. Esses, por sua vez, surgem da dificuldade na pega e desconhecimento sobre a prática da amamentação, principalmente sobre o posicionamento durante as mamadas, a percepção equivocada de que leite é fraco ou, ainda, que a produção de leite materno é insuficiente.

Diante do exposto, percebe-se a necessidade de orientação e apoio adequados dos profissionais de saúde e da família da adolescente no processo de amamentação. Portanto, é necessário um acompanhamento que deve ser iniciado no pré-natal e desenvolvido ao longo do tempo de forma contínua, dinâmica, processual e interativa, favorecendo também a autonomia e corresponsabilização dos envolvidos, principalmente dos profissionais da atenção primária à saúde no que diz respeito à adolescência e ao aleitamento materno. Com a divulgação dos achados deste estudo, espera-se que hajam ações de cuidado direcionadas a essa parcela da população, compreendendo suas necessidades e singularidades.

\section{REFERÊNCIAS}

1 - OPAS. Ação Global Acelerada para a Saúde de Adolescentes (AA-HA!): Guia de orientação para apoiar a Implementação pelos países. Washington, DC: Organização Pan-Americana da Saúde; 2018.

2 - Brasil. Ministério da Saúde. Proteger e cuidar da saúde de adolescentes na atenção básica. Brasília: Ministério da Saúde; 2017.

3 - Fiedler MW, Araújo A, Souza MCC. A prevenção da gravidez na adolescência na visão de adolescentes. Texto Contexto - Enferm. 2015; 24(1):30-7. DOI: 10.1590/0104$\underline{07072015000130014}$

4 - Bigaton UL (Coord). Maternidade precoce: Enfrentando o desafio da gravidez na adolescência. Brasília: UNFPA; 2013.

5 - World Health Organization (WHO). Adolescent pregnancy: Fact sheet. Washington: WHO; 2014 [citado em 15 mar 2018]. Disponível em: http://www.who.int/mediacentre/factsheets/fs3 64/en/index.html

6 - Brasil. Ministério da Saúde. Saúde Brasil 2015/2016: Uma análise da situação de saúde e da epidemia pelo vírus Zika e por outras doenças transmitidas pelo Aedes aegypti. Brasília: Ministério da Saúde; 2017.

7 - Brasil. Ministério da Saúde. Informações de Saúde. Estatísticas Vitais. Datasus 2016 [citado em 15 jan 2018]. Disponível em: http://www2.datasus.gov.br/DATASUS/index.php ?area $=0205 \&$ id $=6936 \& V O b j=h t t p: / /$ tabnet.datas us.gov.br/cgi/deftohtm.exe?sinasc/cnv/nv

8 - Brasil. Ministério da Saúde. Saúde da criança: Aleitamento materno e alimentação complementar. Brasília: Ministério da Saúde; 2015.

9 - Horta BL, Victora CG. Long-term effects of breastfeeding. Geneva: WHO; 2013.

10 - Silva PS, Moraes MS. Caracterização de parturientes adolescentes e de seus conhecimentos sobre amamentação. Arq Ciênc Saúde 2011 [citado em 15 mar 2018]; 18(1):2835. Disponível em: http://repositorioracs.famerp.br/racs ol/vol-18-1/IDS\%204\%20-

\%20jan-mar\%202011.pdf

11 - Maranhão TA, Gomes KRO, Nunes LB, Moura LNB. Fatores associados ao aleitamento materno exclusivo entre mães adolescentes. Cad Saúde Colet. 2015;23(2):132-9. DOI: 10.1590/1414462X201500020072

12 - Sehnem GD, Tamara LB, Lipinski JM, Tier CG. Vivência da amamentação por mães adolescentes: Experiências positivas, ambivalências e dificuldades. Rev Enferm UFSM 2016;6(4):578-88. DOI: $10.5902 / 2179769223707$ 13 - Minayo MCS (Org). Pesquisa social: Teoria, método e criatividade. 38a ed. Petrópolis, RJ: Vozes; 2016.

14 - Instituto Brasileiro de Geografia e Estatística (IBGE). Panorama das cidades: Divinópolis. Brasília: IBGE; 2018 [citado em 15 mar 2019]. Disponível em: https://cidades.ibge.gov.br/brasil/mg/divinopolis Lpanorama

15 - Bardin L. Análise de conteúdo. São Paulo: Edições 70; 2016.

16 - Gradim CVC, Ferreira MBL, Moraes MJ. O perfil das grávidas adolescentes em uma unidade de saúde da família de Minas Gerais. Rev APS 2010 [citado em 15 mar 2018]; 13(1):55-61. Disponível em: http://ojs2.ufjf.emnuvens.com.br/aps/article/vie w/14358. Acesso em 08 abr.2019

17 - Ribeiro KR, Istoe RSC, Castro FM, Shimoda E. Associação entre gravidez na adolescência, prática do bullying e evasão escolar em escola pública de Campos dos Goytacazes, RJ, Brasil. Inter Science Place 10(1):186-243. DOI: 106020 
18 - Resta DG, Marqui ABT, Colomé ICS, Jahn AC, Eisen C, Hesler LG, et al. Maternidade na adolescência: Significado e implicações. Reme, Rev Min Enferm. 2010 [citado em 15 mar 2018];

14(1):68-74. Disponível em: http://www.reme.org.br/artigo/detalhes/89

19 - Spindola T, Oliveira ACFC, Cavalcanti RL, Fonte VRF. Amamentação na adolescência: Histórias de vida de mães primíparas. J Res Fundam Care 2014;6(1):414-24.

DOI: $10.9789 / 2175-5361.2014 v 6 n 1 p 414$

20 - Conde RG, Guimarães CMS, Gomes-Sponholz FA, Oria MOB, Monteiro JCS. Autoeficácia na amamentação e duração do aleitamento materno exclusivo entre mães adolescentes. Acta Paul Enferm. 2017;30(4):383-9. DOI: 10.1590/1982$\underline{0194201700057}$

21 - Negin J, Coffman J, Vizintin P, RaynesGreenow C. The influence of grandmothers on breastfeeding rates: A systematic review. BMC Pregnancy Childbirth 2016;16(1):91-100. DOI: 10.1186/s12884-016-0880-5

22 - Clapis CV, Fabbro MRC, Beretta MIR. A prática da amamentação de mães adolescentes nos primeiros seis meses de vida do filho. Cienc Cuid Saúde 2013;12(4):704-10. DOI: 10.4025/cienccuidsaude.v12i4.20911

23 - Macedo MDS, Torquato IMB, Trigueiro JVS, Albuquerque AM, Pinto MB, Nogueira MF. Aleitamento materno: Identificando a prática, benefícios e os fatores de risco para o desmame precoce. Rev Enferm UFPE 2015;9(1):414-23. DOI: 10.5205/reuol.5221-43270-1-RV.0901supl201521 24 - Prates LA, Schmalfuss JM, Lipinski JM. Amamentação: A influência familiar e o papel dos profissionais de saúde. Rev Enferm UFSM 2014; 4(2):359-67. DOI: 10.5902/2179769210631

25 - Cervellini MP, Gamba MA, Coca K, Abrão ACFV. Lesões mamilares decorrentes da amamentação: Um novo olhar novo para um problema conhecido. Rev Esc Enferm USP 2014; 48(2):346-56. DOI: 10.1590/S0080$\underline{6234201400002000021}$

26 - Mariani Neto, C. Manual de aleitamento materno. 3a ed. São Paulo: Federação Brasileira das Associações de Ginecologia e Obstetrícia; 2015.

Nota: Este artigo apresenta os resultados de uma Dissertação de Mestrado.
Recebido em: 28/09/2018

Aprovado em: 16/04/2019

Endereço de correspondência:

Angela Mendes Taveira

Rua Rua D. Pedro I, 300/102

CEP: 35500-095 - Divinópolis/MG - Brasil

E- mail: angela-taveira@hotmail.com 